\title{
Trichoscopy in Diagnisis of Pili Anulati
}

\section{Assenhaji I*, Baybay H, Sqali GH, Douhi Z, Elloudi S and Mernissi FZ \\ Departement of dermatology Hassan II, FEZ, Morocco}

*Corresponding author: Assenhaji louizi ibtissam, Centre hospitalier, hrazem, BP: 1835 Atlas, Fès, Avenue hassan II, Fès30050, Morocco; Email: assenhaji.louizi@outlook.fr

\section{Case Report}

Volume 5 Issue 1

Received Date: February 11, 2020

Published Date: February 28, 2020

DOI: $10.23880 /$ cdoaj-16000206

\section{Abstract}

Pili annulati is an autosomal dominant hair shaft disorder characterized by alternating light and dark bands in hairs of affected individuals. Trichoscopy remains a non-invasive tool to suspect this disorder, confirmed by the examination with polarized light.

Keywords: Pili annulati; Scalp psoriasis; Dermocoticoid

\section{Introduction}

PILI annulati, or ringed hair, is a rare anomaly of keratin formation in which the hair shafts characteristically shows bright and dark bands when viewed by reflected light.

We present the case of a patient who presents the pili annulati decouvert in trichoscopy.

\section{Case Report}

We report the case of a 10-year-old girl, followed for a scalp psoriasis treated with dermocoticoid with good progress. In whom the dermatological examination had revealed shiny hair (Figure 1).

Hair trichoscopy showed an alternation of light and dark bands typical of pili annulati (Figure 2).

The capillary rod examined under polarized light showed an alternation of dark and light zones at regular intervals along their entire length in favor of pili annulati (Figure 3 ).

Biological examinations performed to detect an associated autoimmune pathology were normal.
The clinical and trichoscopic examination of the mother's hair was normal.

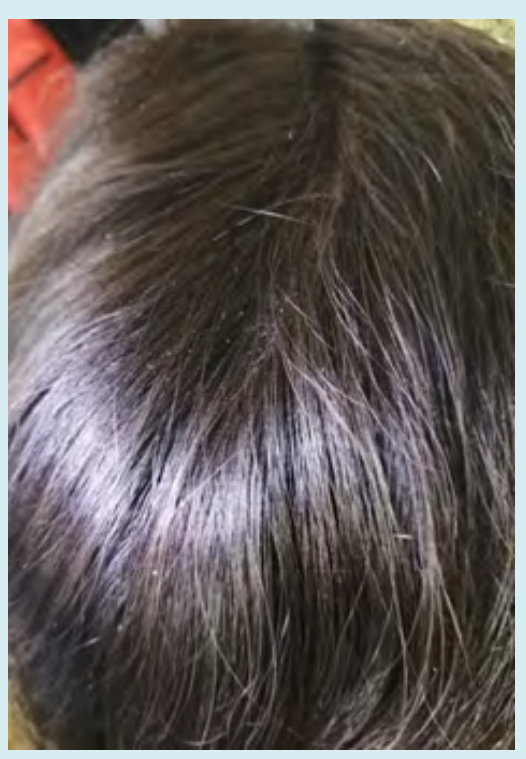

Figure 1: Clinical image showing shiny hair. 


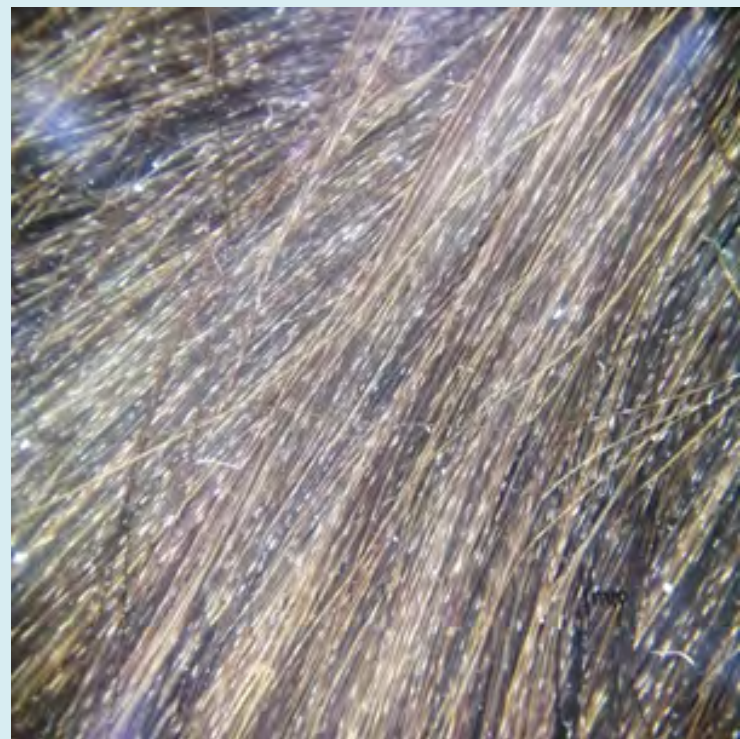

Figure 2: Trichoscopy of the shiny hair of the second girl showing alternation of light and dark bands.

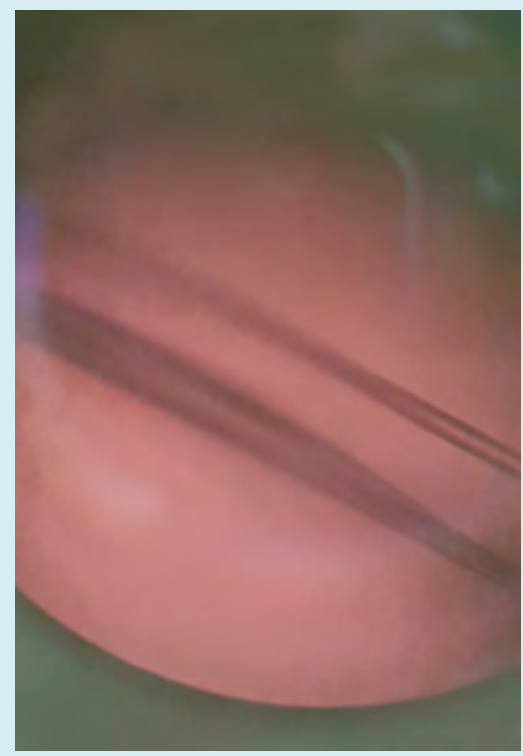

Figure 3: Polarized light showing an alternation of dark and light areas over their entire length.

\section{Discussion}

Pili annulati is an autosomal dominant hair shaft disorder characterized by alternating light and dark bands in hairs of affected individuals [1]. However, sporadic cases have also been described [2].

The abnormality is caused by the presence of air-filled cavities within the hair shaft [1].

Usually there is no clinical problem with hair growth, and there are no associated abnormalities of the skin or other organs [3].

In pili annulati trichoscopy shows hair shafts with alternating light and dark bands. Usually about $20-80 \%$ of hairs are affected. Trichoscopy remains a non-invasive tool to suspect this disorder, confirmed by the examination with polarized light.

There is no treatment for this disorder, but the prognosis is good and hair growth is usually normal [2].

\section{References}

1. Miteva M, Tosti A (2013) Dermatoscopy of hair shaft disorders. J Am Acad Dermatol 68(3): 473-481.

2. Teysseire S, Weiler L, Thomas L, Dalle S (2017) Pili anulati. Annales de Dermatologie et de Vénéréologie 144(5): 399-400.

3. Price VH, Thomas RS, Jones FT (1968) Pili annulati. Optical and electron microscopic studies. Arch Dermatol 98(6): 640-647. 